\title{
Selenium Speciation in Biofilms from Granular Sludge Bed Reactors Used for Wastewater Treatment
}

\author{
Eric van Hullenbusch ${ }^{1}$, François Farges ${ }^{2,3}$, Markus Lenz ${ }^{4}$, Piet Lens ${ }^{4}$ and Gordon \\ E. Brown Jr. ${ }^{2,5}$ \\ 1 Laboratoire des Géomatériaux, Université de Marne la Vallée, France \\ 2 Dept. of Geological and Environmental Sciences, Stanford University, Stanford, CA 94305-2115, USA \\ 3 USM 201 "Minéralogie", UMR CNRS 7160, Muséum National d'Histoire Naturelle, Paris, France \\ 4 Sub-dept. of Environmental Technology, Wageningen Universitaet, 6700 EV Wageningen, The Netherlands \\ 5 Stanford Synchrotron Radiation Laboratory, SLAC, MS 69, 2575 Sand Hill Road, Menlo Park, CA 94025, USA
}

\begin{abstract}
Se K-edge XAFS spectra were collected for various model compounds of Se as well as for 3 biofilm samples from bioreactors used for Se-contaminated wastewater treatment. In the biofilm samples, Se is dominantly as $\mathrm{Se}(0)$ despite Se K-edge XANES spectroscopy cannot easily distinguish between elemental Se and Se(-I)-bearing selenides. EXAFS spectra indicate that Se is located within aperiodic domains, markedly different to these known in monoclinc red selenium. However, Se can well occur within nanodivided domains related to monoclinic red Se, as this form was optically observed at the rim of some sludges. Aqueous selenate is then efficiently bioreduced, under sulfate reducing and methanogenic conditions.
\end{abstract}

Keywords: Se, biofilms, sludge, bioreduction, XANES, EXAFS

PACS: $61.10 . \mathrm{Ht}$, 87.64.Fb, 91.62.Bf, 91.62.De, 91.62.+g, 82.39.-k, 91.62.J

\section{INTRODUCTION}

The toxicity and bioavailability of selenium (Se) largely depends on the chemical oxidation state of the element. Se is present in the environment in five different oxidation states (-II, -I, 0, IV and VI) as a variety of inorganic (selenides, elemental selenium, selenite, selenate) and organic (amino-acids and methylated) compounds. Relatively low concentrations of soluble selenate $\left(\mathrm{SeO}_{4}{ }^{2-}\right)$ and selenite $\left(\mathrm{SeO}_{3}{ }^{2-}\right)$ in the water body can result in disastrous effects on ecosystem level, as Se tends to bioaccumulate. Elemental Se has been commonly considered as bio-unavailable form of Se because of its insolubility. Under strongly reducing conditions, selenides (i.e., $\mathrm{Se}(-\mathrm{II})$ and $\mathrm{Se}(-\mathrm{I})$ ) are thermodynamically stable and form insoluble metal selenide precipitates. Biological processes for the removal of soluble selenium were mainly described for different natural inocula (soil and sediments) from which most of the bacteria able to reduce selenate or selenite were isolated [1,2]. The end products of this reduction are manifold, including elemental selenium, hydrogen and metal selenides but also organo-selenium compounds (Se amino acids and volatile compounds) [3]. Selenium bioreduction in the treatment of mining effluents and agricultural drainage waters and the capacity of biological selenate removal of anaerobic granular sludge biofilms harboring numerous bacterial strains has been recently investigated in batch conditions $[4,5]$. The capacity of anaerobic granular sludge biofilms to reduce selenate from contaminated wastewater was investigated at labscale continuous bioreactors conditions and the present study investigated the speciation of selenium accumulated in the biofilms investigated by X-ray absorption fine structure (XAFS) spectroscopy at the Se K-edge.

\section{SOURCE OF BIOFILMS}

Anaerobic granular sludge biofilm originates from a full-scale upflow anaerobic sludge blanket (UASB) reactor treating paper mill wastewater (Industrie Eerbeek B.V., Eerbeek, The Netherlands; Fig. 1). These biofilms were used to inoculate the bioreactors. Sulfate reducing bacteria can reduce selenate using enzymes of the dissimilatory sulfate reduction pathway [6]. Consequently the bioreactors were fed with lactate and selenate $\left(10 \mu \mathrm{M}\right.$ as $\left.\mathrm{Na}_{2} \mathrm{SeO}_{4}\right)$ in the presence and absence of sulfate (reactors labeled "R2" 
and "R3", respectively) at a $\mathrm{COD} / \mathrm{SO}_{4}$ ratio $=0.5$, an organic loading rate (OLR) of $5 \mathrm{~g}$ chemical oxygen demand (COD)/L*day and an hydraulic residence time (HRT) of 6 hours. The pH was buffered at 7.0 with 40 $\mathrm{mM}$ of Na-dihydrogenophosphate solution.). These experiments aim to measure the influence of sulfate reducers on selenate bioreduction as well as the speciation of selenium accumulated in the biofilms. A third reactor ("R1") received influent $\mathrm{SeO}_{4}{ }^{2-}(500 \mu \mathrm{M})$ and ethanol as electron donor. In contrast, reactor R2 continuously received influent $\mathrm{SeO}_{4}{ }^{2-}$ at $10 \mu \mathrm{M}$. Biofilms were sampled 115 days after the onset of reaction for the $\mathrm{R} 2$ and $\mathrm{R} 3$ reactors (samples 10 and 11, respectively). The sludge samples 10 and 11 contained 81 and $189 \mu \mathrm{g}$ Se per $\mathrm{g}$ wet weight respectively. For sample 9, the reactor R1 was sampled after 14 days.

TABLE 1. Se-model compounds studied.

\begin{tabular}{|c|c|c|c|}
\hline Name & $\begin{array}{c}\mathrm{Se} \\
\text { redox }\end{array}$ & Origins & $\begin{array}{c}\text { Chemical } \\
\text { formula }\end{array}$ \\
\hline $\begin{array}{c}\text { sodium } \\
\text { selenate }\end{array}$ & VI & synthetic & $\mathrm{Na}_{2} \mathrm{SeO}_{4}$ \\
\hline $\begin{array}{c}\text { sodium } \\
\text { selenite }\end{array}$ & IV & synthetic & $\mathrm{Na}_{2} \mathrm{SeO}_{3}$ \\
\hline chalcomenite & IV & natural & $\mathrm{CuSeO}_{3} \bullet 2\left(\mathrm{H}_{2} \mathrm{O}\right)$ \\
\hline $\begin{array}{c}\text { native } \\
\text { trigonal gray }\end{array}$ & 0 & natural & $\mathrm{Se}(0)$ \\
\hline $\begin{array}{c}\text { glassy } \\
\text { gray }\end{array}$ & 0 & synthetic & $\mathrm{Se}(0)$ \\
\hline $\begin{array}{c}\text { red } \\
\text { monoclinic }\end{array}$ & 0 & synthetic & $\mathrm{Se}(0)$ \\
\hline krutaït & -I & natural & $\mathrm{CuSe}_{2}$ \\
\hline ferroselite & -I & synthetic & $\mathrm{FeSe}_{2}$ \\
\hline penroseite & -I & natural & $\mathrm{NiSe}_{2}$ \\
\hline berzelianite & -II & natural & $\mathrm{Cu}_{2} \mathrm{Se}$ \\
\hline Se-digenite & -II & natural & $\mathrm{Cu}_{9}\left(\mathrm{~S}_{2}, \mathrm{Se}_{5}\right.$ \\
\hline klockmannite & -II & natural & $\mathrm{CuSe}_{2}$ \\
\hline stilleite & -II & synthetic & $\mathrm{ZnSe}$ \\
\hline tyrrellite & -II & natural & $\mathrm{CuCo}_{2} \mathrm{Se}_{4}$ \\
\hline
\end{tabular}

\section{XAFS SPECTROSCOPY}

XAFS experiments were performed in-situ (e.g., under anoxic conditions) at the BL 11-2 (SSRL, Stanford, USA), using a focused beam $(0.2 \times 0.5 \mathrm{~mm})$. We used a $\mathrm{Si}(220)$ double-crystal monochromator and $0.5 \mathrm{~mm}$ vertical height slits apertures and ensure highresolution conditions. A Lytle-detector was used to collect the $\mathrm{Se} \mathrm{K} \alpha$ fluorescence radiation. Photoreduction/oxidation phenomena were carefully checked but none were observed. A series of model compounds (natural and synthetic) with variable selenium redox state were studied. Table 1 lists these samples and their Se-valence. For elemental Se, we studied 3 polymorphs (trigonal native $\mathrm{Se}$, red monoclinic and glassy aperiodic black modifications). Also, the fact that selenides can adapt two valences, namely $\mathrm{Se}(-\mathrm{II})$ and $\mathrm{Se}(-\mathrm{I})$ (Table 1) was investigated in detail.

\section{RESULTS}

Figure 2 shows the normalized Se K-edge XANES spectra collected for a selection of model compounds with characteristic selenium valences. The Se K-edge position is sensitive to the valence of Se [3,7-10]. In contrast to previous studies, no simple relation is found between the Se K-edge position and the selenium valence. This is because selenides can adapt two valences (-II and $-\mathrm{I}$, respectively). The edge position for $\mathrm{Se}(-\mathrm{I})$ is $1.4(2) \mathrm{eV}$ before that for $\mathrm{Se}(-\mathrm{II})$. However the edge position for $\mathrm{Se}(-\mathrm{I})$ (as in $\mathrm{FeSe}_{2}$ and $\left.\mathrm{CuSe}_{2}\right)$ is identical to that for elemental Se $(\sim 12659.7$ $\mathrm{eV}$ in our study). We did not select the edge crest maxima to derive valences (see [10]) because this region is also affected by the local structures around Se. It is therefore unreliable for this purpose. Figure 3 shows the Se K-edge XANES spectra for the various

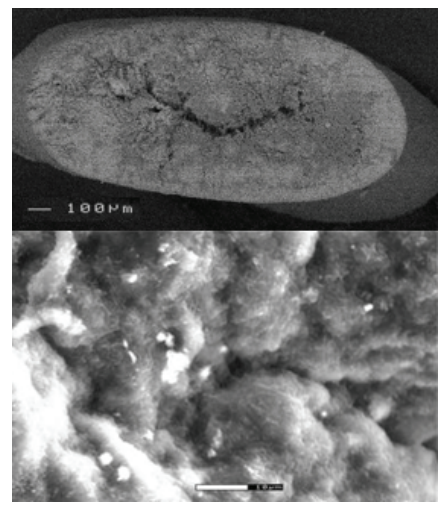

FIGURE 1. ESEM images of an inoculum (top) and the sludge sample 11 (bottom). Note the bright spots, rich in Se.

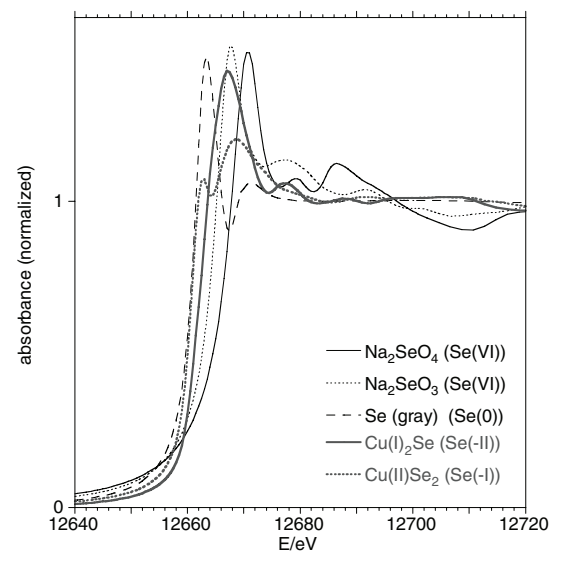

FIGURE 2. Normalized Se K-edge XANES for selected model compounds.

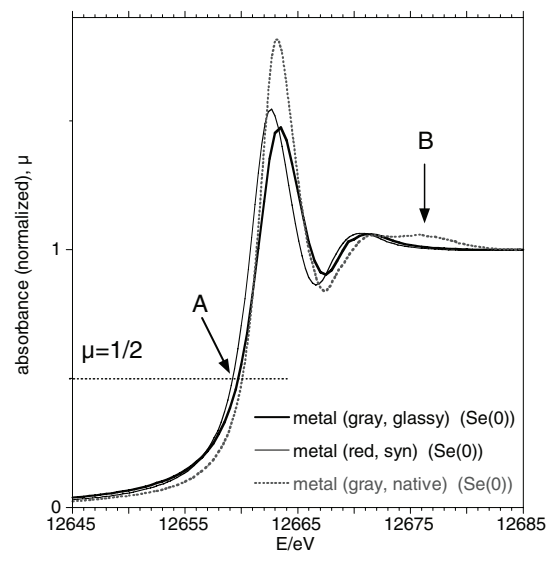

FIGURE 3. Normalized Se K-edge XANES for various elemental Se. 


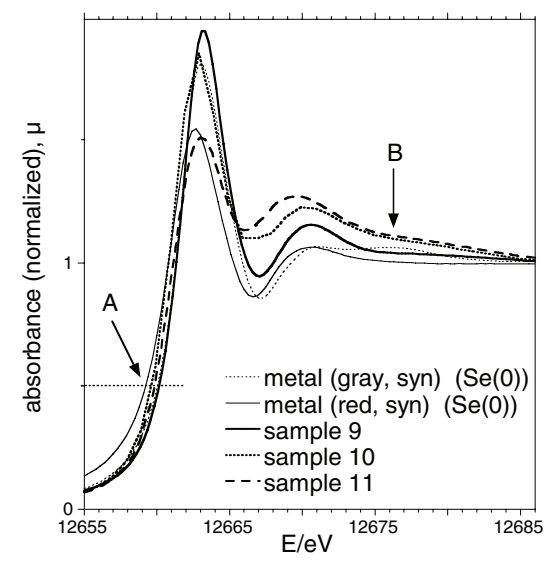

FIGURE 4. Normalized Se K-edge XANES for selected model compounds.

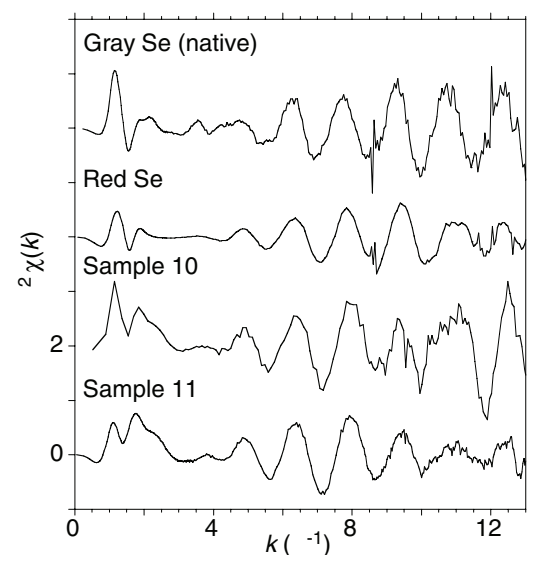

FIGURE 5. $\mathrm{k}^{2}$-weighted normalized EXAFS spectra for two elemental Se samples as compared to two sludges.

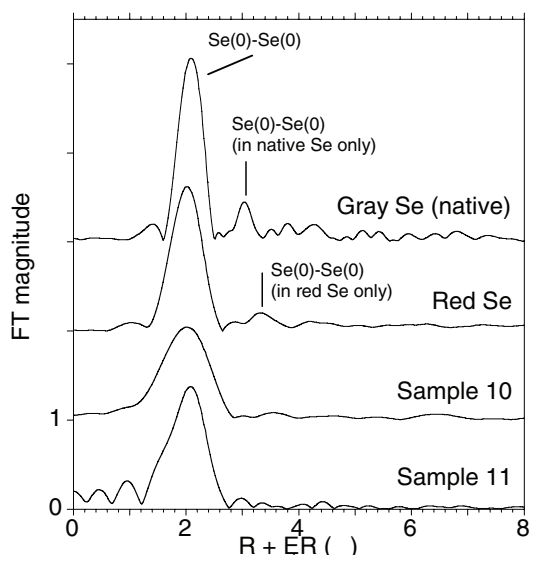

FIGURE 6. Fourier Transforms of EXAFS spectra (Fig. 5). elemental Se samples. Their edge positions (feature A) are similar. In contrast, feature B is absent in the low symmetry modifications (red monoclinic and glassy). Figure 4 shows the Se K-edge normalized XANES spectra collected for samples 9, 10 and 11 from the bioreactors R1, R2 and R3, respectively. The edge position (feature A) is similar to that for $\mathrm{Se}(0)$ (to which the main XANES resemble) or Se(I). Feature B is absent in any of the sludge samples.

Figure 5 shows the $\mathrm{k}^{2}$-weighted normalized EXAFS spectra for trigonal and monoclinic elemental Se as well as for samples 10 and 11. Figure 6 shows the Fourier Transform (FT) of the EXAFS spectra shown on Fig. 5. The EXAFS and FT spectra for the elemental Se show Se-Se pairs near $2.05 \AA$ (uncorrected for backscattering phase-shifts). Second neighbor Se are located at 3.05 and $3.35 \AA$ for the trigonal and monoclinic polymorphs. In contrast, the EXAFS and FT spectra for samples 10 and 11 show only Se first neighbors near $2.05 \AA$ on the FT. Therefore, it appears that, based on the present XANES, EXAFS and FT information for the samples 10 and 11 that $\mathrm{Se}$ is present in these samples dominantly as some aperiodic form of elemental $\operatorname{Se}(0)$ (that remains still unknown to our compound database). However, Se(-I)-bearing selenides can also contribute significantly to the XAFS spectra. Nevertheless, no significant presence $(<10$ atom\%, equivalent to $<2 \mu \mathrm{g} / \mathrm{g}$ wet sludge total oxidized $\mathrm{Se}$ ) for $\mathrm{Se}(-\mathrm{II})$-bearing selenides nor oxidized forms of Se can be detected in any of these samples. Despite monoclinic red Se was optically observed on some sludges out from the reactors, the possibility for nanodivised elemental $\mathrm{Se}$ (close to the red modification) is not excluded.

\section{CONCLUSIONS}

Aqueous Se (selenate) is efficiently bioreduced, both in the sulfate reducing and methanogenic reactor. Under high selenate load (as in reactor R1), selenate is also reduced after 14 days. More work is required, especially at the $\mu$-, and nm scales to better understand the speciation of Se in these biomaterials.

\section{ACKNOWLEDGMENTS}

The staff of SSRL are thanks for their help in data collection, particularly J. Rogers and J.R. Bargar.

\section{REFERENCES}

1. M. Ike, K. Takahashim, T. Fujita, M. Kashiwa and M. Fujita., Water Res. 34, 3019-3025 (2000).

2. M.P. de Souza, A. Amini, M.A. Dojka, I.J. Pickering, S.C. Dawson, N.R. Pace and N. Terry, Appl. Env. Microbiol. 67, 3785-3794 (2001).

3. G. Sarret, L. Avoscan, M. Carrière, R. Collins, N. Geoffroy, F. Carrot, J. Covès and B. Gouget, Appl. Environ. Microbiol., 71, 2331-2337 (2005).

4. V. Astratinei V., E.D. van Hullebusch and P.N.L. Lens, J. Environ. Qual. in press, (2006).

5. M. Lenz, A. Gmerek and P.N.L. Lens, Intern. J. Environ. Anal. Chem. 86, 615-627 (2006).

6. S. Hockin and G.M. Gadd, Environ Microbiol. 8, 816826, (2006).

7. I.J. Pickering, G.E. Brown Jr. and T.K. Tokunaga, Environ. Sci. Technol. 29, 2456-2459 (1995).

8. A.S. Templeton, T.P. Trainor, A.M. Spormann and G.E. Brown Jr, Geochim. Cosmochim. Acta 67, $3547-$ 3557 (2003).

9. A.L. Foster, G.E. Brown, Jr. and G.A. Parks, Geochim. Cosmochim. Acta, 67, 1937-1953 (2003).

10. A.L. Ryser et al., Geochem. Trans., 6, 1-11 (2005). 